\title{
Intrapartum Amnioinfusion in Meconium-stained Amniotic fluid: A Case Control study
}

\author{
Dr. Dinobandhu Sahis ${ }^{1}$, Dr. Swapan Das ${ }^{2}$, Dr. Sanjay Sarkar ${ }^{3}$, Dr. Debasish \\ $\mathrm{Char}^{4}$, Dr. Tushar Kanti Saha ${ }^{5}$ \\ 1(PGT, Dept. of Gynae and Obstretics, Bankura Sammilani Medical College \& Hospital, Bankura, India), \\ 2(RMO, Dept. of Gynae and Obstretics, Bankura Sammilani Medical College \& Hospital, Bankura, India), \\ 3(RMO, Dept. of Medicine, Bankura Sammilani Medical College \& Hospital, Bankura, India); 4(RMO, Dept. of \\ Gynae and Obstretics, Bankura Sammilani Medical College \& Hospital, Bankura, India), 5(Asst. Prof., Dept. \\ of Community Medicine, NRS Medical College, Kolkata, India)
}

\begin{abstract}
Objective- The Aim of this study is to investigate Perinatal outcome and the rate of ceserean section following intrapartam amnioinfusion in women with Meconium Stained Amniotic Fluid [MASF].

Method- A total of 100 women at term in labour with meconium stained amniotic fluid were randomised to receive either Transcervical Intrapartum Amnioinfusion with normal saline [50] or routine obstetric care [50]. Perinatal outcome and obstetric outcome were recorded and analysed in both groups.

Result- The ceserean section rate due to fetal distress was $34 \%$ in the control group and $10 \%$ in the study group. Respiratory distress of the neonate was significantly less common in the study group than in the control group [p=0.0053]. The rate of Meconium Aspiration Syndrome [MAS] was $20 \%$ in the control group and $4 \%$ in the study study group. [p=0.0433].

Conclusion- Amniotransfusion in cases of MSAF significantly improved neonatal outcome and decreases the ceserean section rate without increasing any maternal and fetal complications.
\end{abstract}

Keywords: Amnioinfusion, Meconium Stained Amniotic Fluid [MASF], Meconium Aspiration Syndrome [MAS].

\section{Introduction}

The term Meconium is derived from Greek word 'Mekonion' a word for Opium /Poppy Juice Aristotle coined the term Meconium and reported opium like effects in neonates born through Meconium stained amniotic fluid.

Meconium is the first intestinal secretion from fetus. It starts as early as ten weeks of gestation and incidence of intra-uterine passage of Meconium increases with the gestational age.

Amniotic fluid is the fluid present in the amniotic sac which surrounds the fetus provides nutrition and maintains temperature of fetus. The Meconium may be passed during the intrauterine life in about 7 to $22 \%$ cases. Meconium passage is usually secondary to foetal hypoxia. Once Meconium is passed it contaminates amniotic fluid and exposes fetus to Meconium. Many studies have shown Meconium stained amniotic fluid is associated with increase rate of foetal distress increase perinatal morbidity and mortality. Meconium staining of amniotic fluid during labour must be managed by a team of obstetrician and paediatrician well versed in neonatal resuscitation to prevent intra uterine hypoxia, to prevent intra uterine meconium aspiration, and to prevent Meconium aspiration at birth.

Amnio infusion is instillation of ringer lactate / normal saline into amniotic cavity either transabdominally or transcervical. Transcervical amnio infusion is instillation of fluids through cervics during labour once membrane ruptures. Once Meconium stained amniotic fluid is detected during labour, especially in moderate to thick meconium, amnioinfusion is done. Amnioinfusion dilutes and washes away thick Meconium and increase amniotic fluid index. Many studies have shown that amnio infusion in moderate to thick Meconium stained amniotic fluids improves obstetric outcome, decrease in operative delivery and neonatal outcome. However few studies show no improvement in obstetrics or neonatal outcome.

Studies have shown conflicting reports regarding the role of amnioinfusion in Meconium stained amniotic fluid, so these study was conducted to evaluate the role of transcervical amnioinfusion in intrapartum management of Meconium stained amniotic fluid.

\section{Aims and Objectives:}

The present study was conducted in B.S. Medical College, Bankura with the following objectives:

a) The effect of amnioinfusion on neonate by assessing $1 \mathrm{~min}$ and $5 \mathrm{~min}$. Apgar score and sick new born care unit (SNCU) admission. 
b) The effect of amnio infusion in reducing the incidence of Meconium aspiration syndrome and perinatal mortality.

c) To assess the rate of caesarean delivery following intrapartum tramscervical amnioinfusion in women with Meconium stained amniotic fluid.

\section{Materials and Methods}

The current prospective randomized control study was conducted from July 2011 to June 2012 in B.S. Medical College, Bankura. Inclusion and exclusion criteria were as follows:

\section{Inclusion Criteria}

- Woman in labour with Meconium staining of amniotic fluid; singleton pregnancy in cephalic presentation with a gestational age of 37 weeks or more; ruptured membrane with cervical dilatation $<5 \mathrm{~cm}$ and an adequate pelvis.

\section{Exclusion criteria}

- Women were excluded if there was malpresentation, multiple gestation, major foetal anomaly, Chorioamnionitis antepartum haemorraghe, polyhydramnios, cord prolapsed, severe foetal bradecardia and maternal cardiovascular or respiratory diseases.

A total of 100 women at term in early labour with Meconium stained amniotic fluid were randomized to receive either transcervical intrapartum amnioinfusion with normal saline (50) or routine obstetrical care (50). Following an informed written consent all the patients were given a single dose of broad spectal antibiotic intravenously. A 8- size red rubber tube was introduced between foetal head and dilating cervix into amniotic cavity and $500 \mathrm{ml}$ of normal saline was infused over $30 \mathrm{~min}$, this is followed by continuous infusion of normal saline at $3 \mathrm{ml}$ per min. The foetal heart rate and uterine ton were assessed continuously during the intervention. Women were assessed by uterine palpation at 15 min intervals for uterine hypertonic contraction in such cases amnioinfusion was discontinued. Throughout the procedure continuous monitoring of foetal heart rate was done, patient was monitored for pulse, blood pressure temperature every $30 \mathrm{~min}$. Caesarean section were carried out in either group if foetal bradycardia was recorded or in case of non progress of labor.

All neonates were managed by standard protocol of immediate oropharengeal suction followed by endotracheal suction. During foetal oropharengeal suction, the presence of Meconium below the vocal cords was documented. Admission to SNCU and complications including mortality were recorded and X-ray chest of babies of Meconium aspiration syndrome (MAS) was done. All mothers and neonates were followed for 5 to 7 days post natally.

Sample size calculation was done by using Statcalc7.00 (Acastat Software, Leesburg). Finally data found analysed with statistical software Medcalc11.3.0. The differences were expressed considered to statistically significant with $\mathrm{P}$ value $<0.05$ at $95 \%$ C.I.

\section{Results and Analysis:}

A total of 100 women were studied, 50 in each group. The two groups were comparable with respect to age, duration of pregnancy and pregnancy complications as seen in Table-1.

Table-2 shows the outcome of study along with statistical analysis of the results. The caesarean section rate due to foetal distress was $34 \%$ in the control group and $10 \%$ in the study group. The difference was statistically significant $(\mathrm{P}=0.0103)$. Apgar score $<5$ at $1 \mathrm{~min}$ was $50 \%$ in control group and $20 \%$ in study group. The difference was statistically significant $(\mathrm{P}=0.0033)$. Apgar score $<5$ at $5 \mathrm{~min}$ was $4 \%$ in control group and $2 \%$ in study group. Here also $5 \mathrm{~min}$ apgar score was better in study group.

The rate of respiratory distress was $50 \%$ in control group and $16 \%$ in study group. The difference was statistically significant $(\mathrm{P}=0.0053)$. The rate of MAS was $20 \%$ in control group and $4 \%$ in study group. The difference was statistically significant $(\mathrm{P}=0.0433)$ in respect of SNCU Admission the rate was $28 \%$ in control group and $6 \%$ in study group. The difference was statistically significant $(\mathrm{P}=0.0153)$. A laryngoscopic finding of Meconium below the vocal cord in neonates was $42 \%$ in control group and $12 \%$ in study group. The difference was statistically significant $(\mathrm{P}=0.0071)$. There was no perinatal death in study group but only $1(2 \%)$ death in control group. The incidence of puerperial pyrexia was at equal rate in both groups. There was no case of hypertonic uterus in this study. 


\section{Discussion}

Although intrapartum amnioinfusion was introduced more than two decades ago. Reports of its regular use in developing countries were scarce. This is due to lack of specially designed intra-uterine catheta and equipment for electronic foetal monitoring. The findings of the present study are that amnioinfusion is a safe technically feasible and easily affordable procedure in a rural set up where most of the patients are of lower sociao economic status.

As the participants were from same area and similar backgrounds the study and control groups were balanced with respect to socio-demographic variables and baseline obstetric characteristics.

In this study there was no significant difference between study group and control group according to age, gestational age, preeclampsia, post term, previous LSCS, anaemia and birth weight of babies.

In this study there was a trend towards lower caesarean delivery rate in the amnioinfusion group. Incidence in caesarean section was $10 \%$ in the study group as compared to $34 \%$ in control group $(\mathrm{P}<0.05)$. Study by Macri et.al ${ }^{l}$ showed that the rate of caesarean section was significantly reduced in amnioinfusion group. Wenstorm et.al ${ }^{2}$ also showed that patients receiving amnioinfusion had significantly lower incidence of operative delivery.

In our study number of cases with Apgar @ 1 min $<5$ were 20\% in study group as compared to $50 \%$ in control group. There was significant improvement in Apgar score @ 1 min $(\mathrm{P}=0.0033)$ in amnioinfusion group suggesting a lesser need for immediate neonatal intervention for which equipment and trained personnel are often lacking in developing countries. This study correlated with CRAMP ${ }^{3}$ study which showed improvement in 1 min Apgar. In this study number of cases with Apgar @ $5 \mathrm{~min}<5$ were 4\% in control group as compared to $2 \%$ in study group. In our study there was no significant improvement in 5 min Apgar $(\mathrm{P}=1)$. However $\mathrm{CRAMP}^{4}$ meta-analysis study shows significant reduction in incidence of 5 min Apgar $<7$.

In our study meconium below the vocal cord was evident in only $12 \%(6 / 50)$ patients receiving amnioinfusion, compared to $42 \%(21 / 50)$ in the non infusion group of patients $(\mathrm{P}=0.0071)$ similar to the findings of Das et.al ${ }^{5}$ and Rathorea et.al ${ }^{6}$. Meconium aspiration syndrome (MAS) was reduced markedly in amnioinfusion group. It occurred in $4 \%$ of cases in study group and $20 \%$ of cases in control group $(\mathrm{P}=0.0433)$ which was also comparable to those reported by Rathorea et.al ${ }^{6}$. In our study respiratory distress was markedly reduced in amnioinfusion group $8(16 \%)$ compare to $25(50 \%)$ in controls $(\mathrm{P}=0.0053)$. SNCU admission were $14(28 \%)$ in control group compare to $3(6 \%)$ in amnioinfusion group $(\mathrm{P}=0.0153)$. Perinatal mortality in study group was Nil as compared to $2 \%$ in the control group (statistically not significant).CRAMP- $1^{3}$ and CRAMP- $2^{4}$ meta-analysis study shows significant reduction in perinatal morbidity meconium aspiration syndrome and NICU admission in amnioinfused group. On the contrary Fraser et.al ${ }^{7}$ in his study found that amnioinfusion did not reduce the risk of meconium aspiration syndrome or perinatal death.

In our study there was no increased incidence of puerperial pyrexia because of the procedure. Rathorea et.al ${ }^{6}$ and Hofmeyr et.al ${ }^{8}$ also found similar results.

Amnioinfusion reduces high vegal stimulation because of correction of olygo-hydramnios resulting from rupture of membranes. Cord compression induced vegal stimulation also reduced. Amnioinfusion also has a dilution effect on the meconium. Thus it decreases meconium in the trachea and reduces the incidence of MAS and birth asphyxia.

Although as accurate cost benefit analysis of amnioinfusion is difficult, the possible cost savings are enormous. The average cost of caesarean section is about 50-100 times more than that of an amnioinfusion in a same set up. In addition shorter hospital stay reduces the cost of child birth where health resources are overstretched. Furthermore, emergency caesarean section can have serious consequences on maternal health, especially if the operation is performed in a sub-optimal condition in an under resourced facility.

\section{Conclusion}

In our study we found that there was significant reduction in caesarean section rate in the amnioinfusion group as compared to the control group $(\mathrm{P}<0.05)$. There was significant improvement in Apgar (a) 1min $(\mathrm{P}=0.0033)$. There was significant decrease in the incidence of respiratory distress $(\mathrm{P}=0.053)$, meconium below the vocal cord $(\mathrm{P}=0.0071)$ meconium aspiration syndrome $(0.0433)$ and SNCU admission $(\mathrm{P}=0.0153)$. There was no increased incidence of any maternal complications. Therefore intrapartum transcervical amnioinfusion for meconium stained amniotic fluid is a beneficial procedure using simple equipment in the absence of modern electronic foetal monitoring and specialised neonatal care facilities especially in low resource settings.

\section{References}

[1]. Macri C.J. Schrimmer D.B. Leung A, Greenson J.S., Paul R.H. Prophylactic amnioinfusion improves outcome of pregnancy complicated by thick meconium and Oligohydramnios Am J Obset Gynecol $1992 ; 167 ; 117 ; 121$.

[2]. Wenstrom K.D. Parsons MMt. The Prevention of MA in labor using Amnioinfusion. Obstet Gynaecol 1989; 73; 647; 651. 
[3]. Hofmeyr G., Gulmezoglu a.m, Buchmann E., Homrath G.H., Shaw A., Nikodem V.C, Cronje H., Delager M., Mohomed K. The collaborative randomised amnioinfusion for meconium project (CRAMP); South Africa. Br. J. Obstet Gynaecol 19987; 105 (3): 304308 .

[4]. Mohomed K., Mulambo T., Gulmezoglu A.M. collaborative randomised amnioinfusion for meconium project (CRAMP); Zombabwe Br. J. Obstet Gynaecol 1998; 105(3): 309-313

[5]. Das. V, Shrisvata S, Preetikumar, et.al Amnioinfusion during labor complicated by meconium J. Obstet Gynaecol India 2001; 51; $105-7$

[6]. Rathorea AM, Singh R, Ramji S, et.al Randomized trial of amnioinfusion during labor with meconium stained amniotic fluid BJOG, 2002; 109:17-20.

[7]. Fraser WD, Hofmrey J, Lede et.al. Amnioinfusion for the prevention of the meconium aspiration syndrome. NEJM, 2005; 353:909-17.

[8]. Hofmey6r GJ Amnioinfusion for meconium stained liquor in labor. Cochrane Database Syst Rev. 2002; (2):CD 000014.

Table-1: Baseline Data

\begin{tabular}{|c|c|c|}
\hline Characteristic & Study group (n=50) & Control group (n=50) \\
\hline Average Age (years) & 24 (range 18-25) & 23 (range 18-30) \\
\hline Average gestational age (weeks) & 38.5 (range 36.5-40) & $37.8($ range 36.2-40.5) \\
\hline Average birth weight (kg) & $2.5($ range $2.2-2.9)$ & $2.6($ range $2.1-3.0)$ \\
\hline Pregnancy complication & $7(14 \%)$ & $11(22 \%)$ \\
Preeclampsia & $10(20 \%)$ & $16(32 \%)$ \\
Post-term & $5(10 \%)$ & $5(10 \%)$ \\
Previous LSCS & $5(10 \%)$ & $6(12 \%)$ \\
\hline
\end{tabular}

Table-2: Comparison of outcomes in study and control group

\begin{tabular}{|c|c|c|c|c|c|}
\hline \multirow[t]{2}{*}{ Outcome } & \multicolumn{2}{|c|}{ Study group $(n=50)$} & \multicolumn{2}{|c|}{ Control group $(n=50)$} & \multirow[t]{2}{*}{$P$ value } \\
\hline & Number & $\%$ & Number & $\%$ & \\
\hline $\begin{array}{c}\text { Caesarean section for foetal } \\
\text { distress }\end{array}$ & 5 & 10 & 17 & 34 & 0.0103 \\
\hline Forceps delivery & 5 & 10 & 6 & 12 & NS \\
\hline $\begin{array}{l}\frac{\text { Apgar }<5}{1 \mathrm{~min}} \\
5 \mathrm{~min}\end{array}$ & $\begin{array}{c}10 \\
1\end{array}$ & $\begin{array}{c}20 \\
2\end{array}$ & $\begin{array}{c}25 \\
2\end{array}$ & $\begin{array}{c}50 \\
4\end{array}$ & $\begin{array}{c}0.0033 \\
1.000\end{array}$ \\
\hline Respiratory distress & 8 & 16 & 25 & 50 & 0.0053 \\
\hline MAS & 2 & 4 & 10 & 20 & 0.0433 \\
\hline SNCU Admission & 3 & 6 & 14 & 28 & 0.0153 \\
\hline Meconium below the vocal cord & 6 & 12 & 21 & 42 & 0.0071 \\
\hline Perinatal mortality & Nil & - & 1 & 2 & NS \\
\hline Puerperial pyrexia & 1 & 2 & 1 & 2 & - \\
\hline Hypertonic uterus & Nil & & nil & & \\
\hline
\end{tabular}

